\title{
OS PRIMEIROS ANOS DA UNIVERSIDADE FEDERAL DO PARÁ VISTOS ATRAVÉS DA FACULDADE DE MEDICINA
}

\author{
José Maria de Castro ABREU JR ${ }^{1}$ \\ Aristoteles Guilliod de MIRANDA ${ }^{2}$
}

\section{RESUMO}

O trabalho pretende apresentar as disputas entre grupos divergentes durante a criação da Universidade do Pará e os problemas da primeira reitoria, sob a ótica da Faculdade de Medicina, que representava uma força importante nesse período dentro do ensino superior do estado. Os conflitos existentes nos primórdios da instituição são tradicionalmente desconsiderados em abordagens mais convencionais.

Palavras-chave: Ensino superior, universidades, Belém, Pará.

\begin{abstract}
The paper intends to present the disputes between divergent groups during the creation of the University of Pará and the problems of the first rectory, from the point of view of the Faculty of Medicine, which represented an important force in this period within the state higher education. Conflicts at the very begnning of the institution are traditionally disregarded in more conventional approaches.
\end{abstract}

Key-words: Higher education, universities, Belém city, Pará state, Brazil.

\section{RESUME}

Le travail a l'intention de présenter les conflits entre les différents groupes divergents pendant la création de 1 'Université du Pará et les problèmes de le premier rectoratdans la perspective de la faculté de médecine, ce qui représentait une force importante au cours de cette période au sein de l'enseignement supérieur de État. Les conflits qui existaient aux débuts de l'institution sont traditionnellement ignorés dans les approches plus conventionnelles.

Mot-clé : Enseignement Supérieur, Universités, Belém- État du Pará, Brésil

\footnotetext{
${ }^{1}$ Médico Patologista-Hospital Ophir Loiola. Professor da Faculdade de Medicina-UFPA. Doutor em História Social da Amazônia-UFPA. Sócio efetivo do Instituto Histórico e Geográfico do Pará.

2 Médico, cirurgião vascular, Serviço de Cirurgia do Hospital Universitário João de Barros BarrettoUFPA. Doutor em Biologia e Epidemiologia-UFPA. Sócio efetivo do Instituto Histórico e Geográfico do Pará. Sócio Titular Fundador da Sociedade Brasileira de História da Medicina
} 
A criação da Universidade Federal do Pará (UFPA), inicialmente Universidade do Pará (UP), já foi assunto desenvolvido por autores comoMoreira ([1977] 1989), Beckmann (1985),e Fontes (2007).Uma instituição com a dimensão da UFPA, com impacto além da região amazônica, resultou de uma aspiração coletiva, envolvendo diversas áreas do conhecimento. Nosso propósito é abordar os primórdios da UFPA e o papel da Faculdade de Medicina no processo.

\section{TENTATIVAS}

Antes da existência da Universidade Federal do Pará, alguns projetos de criação de universidade no Parásurgiram na primeira metade do século $\mathrm{XX}$, embora diferentes do que compreendemos como instituição de ensino superior ${ }^{3}$. A primeira, em 1910, foi a Universidade Paraense, propondo estudos em cinco áreas: História Natural e dos seres vivos; História das Civilizações; Arte e Literatura; Filosofia; e Linguística e Filologia. Seu intuitoera semear noções científicas e artísticas, em cursos e conferências. (A PROVÍNCIA DO PARA, 1910 p. 02). Logo após à nota de fundação, a iniciativa caiu no esquecimento.

Em 1912, um grupo de "magistrados, advogados, engenheiros, dentistas, agrimensores, professores e médicos"pensou em criar uma universidade. Uma comissão foi formada para estudar a organização, devendo apresentar o parecer na reunião seguinte (Estado do Pará, 1912, p. 01). Depois desta notícia, a iniciativa esfriou. Novamente a investida por uma universidade não frutificou.

A tentativa mais duradouraocorreu em 1924: a Universidade Livre do Pará, fundada por Fran Pacheco, cônsul de Portugal no estado, e destinada a "manter cursos avulsos sobre diferentes matérias, com base em palestras e conferências e não em regime de aulas, visando uma formação cultural de ideias gerais" (MOREIRA, 1989, p.14), ou seja: difundir o conhecimento de maneira a estimular a inteligência do brasileiro criando uma nova mentalidade (SÁ, 2006).

\footnotetext{
${ }^{3}$ Pela Lei de Diretrizes e Bases da Educação Nacional, "universidades são instituições pluridisciplinares de formação dos quadros de nível superior, de pesquisa, de extensão e de domínio de cultivo do saber humano" (BRASIL, 1996)
} 
O projeto da Universidade Livre era simples: quem desejasse propagar um ramo do conhecimento poderia se inscrever como professor e proferir conferências; os estudantes seriam qualquer um que desejasse assisti-las. Seus dirigentes eram Henrique Santa Rosa, Oscar de Carvalho e Alcides Gentil, efetivos;e suplentes Inácio Moura, Augusto Borborema e Camilo Salgado. A sede provisória foi o Grêmio Literário Português (Diário de São Luiz, 1924, p.4).

Várias conferências foram realizadas ao longo daquele ano de fundação. A primeira, em 15 de junho, pelo engenheiro Henrique Santa Rosa, versou sobre "Belém e sua topografia", (Estado do Pará, 1924, p. 02; MOREIRA, 1989, p. 15). Na sequência, em junho, o médico Jayme Aben-Athar discorreu sobre longevidade (A Província do Pará, 1924, p. 02); em julho, Cândido Costa falou sobre a imigração japonesa na Amazônia (A Província do Pará, 1924, p. 02).

No mês de agosto, a conferência de José da Costa Castro foi sobre o "Relatório da Missão Britânica e o desenvolvimento do complexo problema cambial" (A Província do Pará, 1924, p. 02). Em setembro, o padre Florêncio Dubois, discorreu sobre "As Cátedras" (A Província do Pará, 1924, p. 02). Em novembro, em parceria da Universidade Livre do Pará com a Associação dos Novos, o Dr. Oscar de Carvalho discorreu sobre "Cultura física, beleza feminina e militarismo", seguido por programação litero-musical. A partir daí, nada mais foi noticiado sobre a Universidade Livre. Para Eidorfe Moreira (1989, p.15) a instituição traduziu-se mais em planos e intenções do que em atos concretos: "a semente de uma nobre ideia que mal chegou a vingar".

A criação do Ministério da Educação, nos anos de 1930, e a edição do Decreto $\mathrm{n}^{\circ}$ 19.851/1931,o Estatuto das Universidades Brasileiras (BRASIL, 1931), fez retornar o desejo criador de universidades, logo surgindo as de São Paulo e de Porto Alegre (MOREIRA, 1989, p.15), na "mais positiva e inteligente reforma já feita no Brasil, definindo os caminhos do ensino superior brasileiro (BECKMANN, 1985, p.509).

A nova legislação repercutiu na Faculdade de Medicina e Cirurgia do Pará, surgindo ali, em 1931, a ideia de criação de uma universidade, de cunho estadual, unindo as Faculdades de Medicina, Direito e a então recém-criada Faculdade de Engenharia (FMCP, Livro de Ofícios Expedidos, 1931). 
Segundo Beckmann (1985, p. 509), naquela maré montante revolucionária dos anos 1930 chegaram novas ideias e conceitos. O clima político, a situação social, a nova lei do ensino, favoreciam a criação da universidade, contudo, tudo ficou novamente no plano das intenções, não obstante o esforço de seus animadores (MOREIRA, 1989, p.19).

\section{A UNIVERSIDADE QUE A MEDICINA NÃO QUIS}

O tema 'universidade' reapareceu em 1942, novamente na Faculdade de Medicina e Cirurgia do Pará, com o Diretor de Educação de Cultura do Estado, o Dr. Miguel Pernambuco Filho, propôs ao Conselho Técnico Admirativo (CTA) da instituição, fundar uma universidade na capital do estado, agrupando as quatro faculdades então existentes em Belém ${ }^{4}$, a ser dirigida por uma associação civil criada com esse objetivo (FMCP, 1942).

Pelo projeto, as escolas de medicina e engenharia manteriam sua personalidade jurídica, seu patrimônio e suas condições de ordem de técnica e administrativa; direito e engenharia continuariam mantidas pelo Estado, sendo acrescidos novos cursos formando a Faculdade de Filosofia e a Escola de Química. A universidade obedeceria às leis de ensino eseu reitor nomeado pelo governo do Estado, a partir de uma lista tríplice (FMCP, 1942).

A posição da Faculdade de Medicina e Cirurgia do Pará seguiu o parecer do professor Carlos Arnóbio Franco: mesmo elogiando a iniciativa, a Faculdade foi contra a proposta afirmando ser "imensa a distância entre a incontestável beleza da idéa e as possibilidades de sua realização nesse momento...". Outro motivo era a incapacidade financeira do governo estadual em manter uma instituição de tal porte; também que o reitor deveria ser escolhido pelo voto livre da Assembleia Universitária e não pelo governador; e principalmenteque a Faculdade de Medicina se absorvida pela universidade, perderia sua autonomia e liberdade, sendo este o argumento mais repetido ao longo do parecer (FMCP, 1942).

\footnotetext{
${ }^{4}$ Cronologicamente: Direito (1902), Farmácia (1904), Odontologia (1914) e Medicina (1919). Embora fundada em 1904, a Faculdade de Farmácia não funcionou entre 1938 a 1945 (Miranda, 2013). Na época da manifestação do CTA, só estavam em atividade: Direito, Odontologia, Medicina e Engenharia. Esta última a mais nova, fundada em 1931 (Moreira, 1989, p.15).
} 
A criação da Universidade do Pará, pelo menos em 1942, não sensibilizou a escola médica do Largo de Santa Luzia ${ }^{5}$.

\section{OUTRA CHANCE}

Mais uma tentativa do sonho universitário surgiu com a constituição de 1946, que previaa aplicação de $3 \%$ de recursos da União, por vinte anos consecutivos, em projetos de valorização da Amazônia. Relator do projeto, o senador ÁlvaroAdolpho da Silveira lembrou a oportunidade de criar uma Universidade Rural da Amazônia, visando os problemas de produção de riquezas e uniformização dos métodos de exploração e racionalização desta produção.

Em 1955, o Primeiro Plano Quinquenal da Amazônia contemplava a criação de uma Universidade da Amazônia, com a construção de uma estrutura física específica, ao invés de auxílios esparsos para melhoria nas faculdades existentes. O Plano não foi aprovado no Congresso e a Universidade da Amazônia caiu no esquecimento (MOREIRA, 1989, p. 20).

\section{A LENTA MATERIALIZAÇÃO DA UNIVERSIDADE DO PARÁ}

A federalização da Faculdade de Medicina, em 1950, foi decisiva para a criação da Universidadefacilitando a federalização das faculdades de direito e farmácia, naquele ano; as três unidades, agora vinculadas ao governo federal,seriam fundamentais para deslanchar a ideia de uma universidade (BECKMANN, 1985). O contexto histórico também favorecia; a educação pública era elemento de modernidade e de integração do país. Pela Guerra Fria, a Amazônia tida como importante para pesquisas científicas e de interesse para a humanidade. A ciência como componente de desenvolvimento e planejamento (FONTES, 2007, p. 17).

Em agosto de 1952, o deputado federal Epilogo de Campos apresentou no Congresso o projeto de criação da Universidade do Pará (BRASIL, 1952), com destaque

\footnotetext{
${ }^{5}$ Em 1944, em discurso pelos vinte e cinco anos de fundação da Faculdade,o então diretor Acylino de Leão, colocou a ideia em pauta, mencionando, também, uma Cidade Universitária em algum ponto incerto do porvir "...tudo enfim, que o progresso nos trará” (Leão, 1945, p.66).
} 
na imprensa, que ressaltou sua importância devido a inexistência de uma universidade no longínquo extremo norte (A Província do Pará, 1952, p. 08).

O projeto previa a junção apenas de três faculdades: medicina, direito e farmácia,com Epílogo por vezesdestacandoas qualidades da Faculdade de Medicina em relação às demais. Para ele, a Faculdade de Medicina era “...sem dúvida a nossa maior vitória no campo do ensino", considerando-a um "grande templo da ciência". E afirmava:

por que se destacou dentre as demais a nossa Escola Médica? Qual o segredo do seu crescimento rápido e sua indiscutível projeção no cenário médico do país? A vida toda da Faculdade de Medicina do Pará está ligada a uma outra existência, tão preciosa como própria da Faculdade e que para a mocidade paraense representará sempre símbolo de tenacidade trabalho e honradez - Dr. Olímpio da Silveira" (A Província do Pará, 1952, p. 08).

Comparando o secretário da Faculdade a um "Jequitibá da Amazônia", Epílogo até mencionava professores importantes da escola médica, mas nada tão elogiosoquanto à figura de Olympio da Silveira: "Este ilustre sergipano que escolheu o Pará para sua terra - pode carregar sob sua fronte a seguinte inscrição: -'Este construiu uma Faculdade"'(A Província do Pará, 1952, p. 08). Epílogo de Campos era tisiologista, formado na Faculdade de Medicina e Cirurgia do Pará,em 1938 e colega de sala de José Rodrigues da Silveira Netto, filho de Olympio da Silveira (MIRANDA \& ABREU JR, 2009). Na década de 1950 concorreu ao Governo do Estado e ao Senado Federal. Foi eleito deputado desde a constituinte de 1946 (MEIRA, 1992, p. 08).

Clodoaldo Beckmann, entrevistado em 2007,criticouo conteúdo do projeto, culpando-o por sua longa tramitação: cinco anos até virar lei. Para Beckmann, o texto era pouco consistente, sem firmar compromissos de uma universidade para com a região amazônica e especialmente com o Pará. "Nada se diz sobre a influência que a universidade haveria de ter no desenvolvimento educacional, científico, tecnológico, cultural e civilizatório do Estado”. Tratava-se de um “...discurso cheio de lugares comuns e louvores a membros dos corpos docente e administrativo das três faculdades federais, citados sem nenhum critério...”, com consequentes omissões (PINTO, 2007, p. 03). 
Para Beckmann, o projeto fora apresentado de forma individualista sem nada havendo sobre “...a audiência e opinião do magistério e do alunado dos cursos superiores de Belém sobre um assunto de tão alta significação”. Essa aparente ausência de participação da sociedade paraense teria tirado as características de "...obra de vida, fruto natural e uma aspiração coletiva" (PINTO, 2007, p. 03).

Em novembro de 1952, a Comissão de Educação da Câmara solicitou informações ao Ministério da Educação e Saúde sobre o projeto da Universidade do Pará. Sete meses depois, o ministério informou existirem outros projetos em tramitação referentes à criação de universidades em diversos Estados. No caso do Pará, laconicamente afirmava que a proposta significava apenas novos encargos para a União, sem benefícios ao ensino superior do país (PINTO, 2007, p. 03).

A resposta do ministério parou o projeto. O próprio ministro da Educação, Simões Filho, era contra a abertura de universidades: "Preferia que, ao invés de universidades, existentes, apenas com um nome pomposo, fossem abertas faculdades diversas, capazes de ministrar ensino com brevidade" (A Província do Pará, 1952 p. 01).

Independente da opinião do ministro, a ideia da universidade resistia, e José Rodrigues da Silveira Netto, então catedrático de Higiene e vice-diretor da Faculdade de Medicina,envolvido com o propósito, apresentou,na IV Semana do Acadêmico de Medicina, a palestra: "Aspectos sôbre a criação da Universidade da Amazônia" (A Província do Pará, 1952, p. 08), destacando os benefícios que aquela organização traria “...aos estudantes da Planície Imensa, além de outros pontos referêntes a sua criação" (IV Semana, 1952, p. 28). Os estudantes, e não somente os de medicina, compraram a ideia. Oziel Carneiro, na época acadêmico de medicina refere:

Eu tinha sido na época de estudante, um dos líderes de um movimento do qual fez parte do Salomão Farregi, Moisés Bentes, José Maria Barbosa, Roberto Santos, o Ricardo Borges Filho, o Alexandre Miranda, o Dhelio Guilhon para criarmos a Universidade do Pará. Eleito presidente da União Acadêmica Paraense, e como tal,parte do conselho da União Nacional dos Estudantes,pelo Pará, fizemos um movimento nacional para trazermos um congresso nacional de estudantes para Belém, visando exatamente desencravar o projeto da Universidade do Pará (...) que não andava.

[No congresso estudantil] Aprovamos a tese para pressionar o Congresso e o Governo Federal a criar a Universidade do Pará 
(...) com apoio do Epílogo de Campos, do deputado Lameira Bittencourt, deputado Armando Correia e outros da época (CARNEIRO, 2012).

O parecer do Ministério da Educaçãocontrário à criação da universidade, não silenciou o movimento. Um precedente foi aberto no ano seguinte, 1954, quando a Câmarafoi favorável à criação da Universidade do Ceará. Ora, se havia recursos para uma universidade no Ceará, por que não em outro estado?

O projeto do Pará tentava prosseguir (A Província do Pará, 1954, p. 16). Mas as divergências políticas locais eram um fator impeditivo. Falando sobre os 30 anos da UFPA, Epílogo de Campos cita o deputado Lameira Bittencourt, que afirmava que a Universidade do Pará só funcionaria quando Magalhães Barata ${ }^{6}$ voltasse ao governo (CAMPOS, 1987); o governador era Zacarias de Assunção, oposição aos baratistas. Na eleição seguinte, para governador, Epílogo concorreu com Magalhães Barata em um pleito complicado e muito disputado, perdendo por poucos votos. Barata assumiu o governo em 1956 (ROCQUE, 2006).

Enquanto a disputa eleitoral ocorria, o projetopassou o ano de 1955 parado. Para a imprensa local, os senadores e deputados das bancadas da Amazônia, ao invés de criarem confusão em torno do assunto, deveriam unir esforços (A Província do Pará, 1955, p. 02).

Em 1956 a União Acadêmica Paraense (UAP), então presidida por Alcyr Meira, estudante de engenharia,pressionava pelaaprovação do projeto. Alcyr recorda: "Foi uma demorada, penosa e, por que não dizer, turbulenta operação logística, num corpo-acorpo com os parlamentares, nem sempre acessíveis, muitas vezes arredios e alguns até mesmo descorteses" (MEIRA, 2007, p.490). Até que o cenário político era mudou, com Magalhães Barata no governo, Lameira Bittencourt, deputado do partido, assumiu a pautaapresentando um projeto substitutivo na Comissão de Finanças da Câmara (A Província do Pará, 1956, p. 16).

\footnotetext{
${ }^{6}$ Joaquim Magalhães Cardoso Barata (1888-1959) assumiu a interventoria do Pará após a Revolução de 1930 até 1935. Retornou ao governo em 1942 como interventor federal. Posteriormente elegeu-se senador, perdendo as eleições para governador em 1950, mas vencendo o pleito seguinte tornando-se Governador constitucional do Estado até sua morte em 1959. Carismático e populista, consquistou o afeto da população pobre e do interior do Estado. Paralelamente também conquistou muitos desafetos sendo temido e acusado de truculento pelos seus opositores (Meira, 1989).
} 
As ações fluíamagora tão bem que a imprensa julgava que, antes do final daquele ano, a universidade estivesse criada. Alcyr Meira, pela UAP, seguia cobrando o deputado Lameira e este informava que, sendo o parecer aprovado pela Comissão de Finanças, iria requerer urgência para apreciação em plenário (A Província do Pará, 1956, p. 01). O ano acabou e a universidade não saiu, porém, parecia cada vez mais viável, considerando os ventos políticos locais soprando favoravelmente à iniciativa.

A UAP seguia firme em sua campanha pela aprovação imediata do projeto de lei, naquela altura ainda em curso no Senado. Em 20 de março de 1957, seus dirigentes, à frente o presidente Sirotheau Corrêa, foram até o Palácio do Governo, após passar por diversos sindicatos e federações, pedindo apoio à causa. Ao governador Magalhães Barata frisaram a importância da aprovação imediata do projeto, sem emendas, pois estas só retardariam o mesmo. Barata afirmou seu total apoio com orientação aos representantes do Partido Social Democrático no senado para aprovarem o projeto sem aceitação de emendas. Garantiu ainda que o projeto seria votado antes de 15 de abril (A Província do Pará, 1957, p. 09).

Em paralelo, conduzida por José Rodrigues da Silveira Netto, aconteceu, na Faculdade de Medicina, a primeira reunião da chamada Comissão de Organização da Universidade do Pará, composta por representantes de todas as faculdades do estado, com as reuniões subsequentes presididas, em sistema de rodízio, por membros de cada faculdade integrantes da comissão, a qual funcionaria até a instalação da Universidade do Pará (A Província do Pará, 1957, p. 10).

Em maio de 1957 regressou da capital federal o estudante Otávio Avertano, representante da UAP em evento da União Nacional dos Estudantes (UNE) ali realizado. Segundo a imprensa local Otávio fora ao Senado saber da tramitação do projeto, sendo informado que este seria levado naquela semana ao plenário e que possivelmente o relator seria o senador Alvaro Adolfo (A Província do Pará, 1957, p. $03)$.

Mesmo fora do prazo, ao menos as coisas aconteciam mais depressa. Em 21 de junho o projeto foi aprovado no Senado e em seguida na Câmara faltando apenas a sanção presidencial (A Província do Pará, 1957, p. 01), o que se deu em 2 de julho de 1957 sendo manchete nos diários locais. 
A Universidade do Pará nasceu da união de sete unidades de ensino: as Faculdades de Medicina, de Direito, de Farmácia, de Odontologia, de Filosofia, Ciências e Letras, de Ciências Econômicas, Contábeis e Atuariais e da Escola de Engenharia (A Província do Pará, 1957, p. 01). O projeto original, com três faculdades, fora ampliado tornando o empreendimento maior e mais sólido e mais viável. A instituição era uma realidade, ao menos legalmente. Contudo, ainda demoraria para se materializar de fato. Muitas questões a serem resolvidas, como os estatutos, e, principalmente, quem seria o reitor?

\section{E A REITORIA FOI PARA...}

Por suas ações, no âmbito da Academia, para a criação da Universidade, José Rodrigues da Silveira Netto, então diretor da Faculdade de Medicina, surgia como candidato natural à reitoria (BECKMANN, 2001). Além do empenho dele, a Faculdade de Medicina, naquele momento, se destacava por ser a instituição com o maior número de funcionários e professores, concorrendo com o maior patrimônio para a formação da universidade, um conjunto arquitetônico mais vistoso e de maior capacidade volumétrica (MOREIRA, 1989, p. 76). Mas o roteiro fugiu ao óbvio.

Em agosto de 1957 chegou em Belém Jurandir Lódi, Diretor Geral da Divisão de Ensino Superior do Brasil, em missão pelo Ministério da Educação e Cultura. Ciceroneado por José Rodrigues da Silveira Netto, juntos visitaram o Dr. Waldyr Bouhid, superintendente do Plano de Valorização Econômica da Amazônia, órgãoliberador de verbas para edificação da estrutura física e manutenção da nova universidade. Visitaram também o Governador do Estado, ajustando medidas para a instalação do novo estabelecimento de ensino. À imprensa, Lodi afirmou que a universidade seria instalada naquele mesmo ano e que os diplomados de 1957 já poderiam utilizar em seus quadros de formatura o título da Universidade do Pará (A Província do Pará, 1957, p. 08).

O estatuto da nova universidade entrou em vigor um mês antes do prazo estabelecido pelo decreto $n^{\circ} 42.427 / 1957$ (MOREIRA, 1989). O regimento, em suas Disposições Transitórias, indicava que o primeiro reitor seria escolhido entre os representantes escolhidos entre os catedráticos das faculdades já previamente 
federalizadas, no caso medicina, direito e farmácia, cada uma indicando um representante, compondo uma lista tríplice a ser enviada ao Presidente da República, para a escolha do reitor (MELLO, 2007).

A Faculdade de Medicina escolheu, por unanimidade, José Rodrigues da Silveira Netto; a Faculdade de Farmácia, Adarezer Coelho, seu diretor. A Faculdade de Direito foi a última a indicar: Mário Braga Henriques, que obteve 13 votos contra um dado a Gonçalvez Bastos, diretor da faculdade, e um para Otávio Meira, outro catedrático.

Mário Braga Henriques parecia uma escolha estranha. Embora catedrático de Direito Comercial, na Faculdade de Direito do Pará, morava havia mais de 10 anos no Rio de Janeiro, à disposição do Governo Federal. Segundo O Estado do Pará Braga Henriques seria o escolhido simplesmente por que estaria "vivamente interessado o Governador do Estado", ou seja, mesmo não constando no regimento, tudo levava a crer que o presidente Juscelino Kubistschek acataria uma indicação de Magalhães Barata (Estado do Pará, 1957, p. 06; A Província do Pará, 1957, p. 08). Mas, tudo ainda era especulação, continuando a expectativa pela escolha do reitor (A Província do Pará, 1957, p. 08).

Ciente do peso do governador na escolha, Silveira Netto tentou uma aproximação com este ainda em agosto, convidando-o para visitar aFaculdade de Medicina. Barata aceitou e,após a visita, enviou ao diretor da faculdade ofício,publicado nos jornais, agradecendo o convite e ressaltando “...o quanto de progresso tem alcançado essa Escola que constituí legitimo orgulho da cultura científica do Pará", entre outras referências elogiosas à instituição, direção e corpo docente, dizendo do imenso prazer que tivera em apreciar os trabalhos efetuados no Departamento de Patologia “...onde constatei o magnífico entrosamento do Estado com a Faculdade no Serviço de Verificação de Óbitos...”(Estado do Pará, 1957, p. 02).

Mesmo apóstanta seda rasgada o efeito não foi o esperado.Para decepção até de quem fazia oposição ao Silveira (OLIVEIRA, 1986), Mário Braga Henriques foi nomeado reitor em 19 de novembro e empossado no dia 28 (MOREIRA, 1989, p. 22). Por não morar em Belém, a posse foi no Rio de Janeiro, no Ministério da Educação, perante o titular desta pasta, ficando de assumir o cargo em Belémemdez dias (A Província do Pará, 1957, p. 06). 
Prevaleceu a vontade do Governador Magalhães Barata, mas como surgiu o nome de Mário Braga Henriques? Radicado no Rio de Janeiro, ondeexercia suas atividades profissionais, Mário era um estranho no Pará, em nada envolvido na luta pela criação da universidade. Sequer gozava do apoio de seus pares na Congregação da Faculdade de Direito, que apoiava Octávio Meira (BECKMANN, 1985).

Para Beckmann (1985) Braga Henriques fora sugestão do diretor da Faculdade de Filosofia, Antônio Gomes Moreira Junior, o qual,convidado pelo governador para ser reitor, declinou do convite por não ser catedrático. O governador então pediu-lhe uma indicação, desde que não fosse Otávio Meira. De uma conversa com Aloysio Chaves e Daniel Coelho de Souza surgiu a indicação de Mário Braga Henriques, satisfazendo o desejo da Faculdade de Direito, de indicar o primeiro reitor da Universidade do Pará.

Em dezembro de 1957 aconteceu a primeira colação de grau pela Universidade do Pará. Pela manhã, a formatura de direito, e, à noite, a de medicina, ambas com a presença do Reitor (A Província do Pará, 1957, p. 12). Um ato com forte simbolismo, embora para os colandos, na prática, a universidade representava apenas umamudança de nome: no diploma, a Faculdade de Medicina e Cirurgia do Pará, passou a ser Faculdade de Medicina da Universidade do Pará.

Ainda em dezembro, na Faculdade de Direito, onde a universidade funcionava de forma precária, com a presença do Reitor, o conselho universitário escolheu o vicereitor. Presentes, pela medicina, José Rodrigues da Silveira Netto, Afonso Rodrigues Filho e Guilherme Chaves; pelo direito, Gonçalves Bastos e Otávio Meira; e pela farmácia Adarezer Coelho da Silva e Aníbal Cardoso. Em votação secreta foi eleito, com cinco votos, Adarezer Coelho; Silveira Netto teve três votos, provavelmente o seu e mais os dois da medicina. (A Província do Pará, 1957, p. 12). Restou continuar como diretor da Faculdade de Medicina.

\section{A REITORIA DE MÁRIO BRAGA HENRIQUES - O HOMEM QUE NÃO ESTAVA LÁ.}

A história oficial da UFPA aponta a indicação política como único fator na escolha do primeiro reitor, com o governador Magalhães Barata pedindo ao presidente 
JK, pelo seu amigo Mário Braga Henriques (FONTES, 2007), deixando em segundo plano as qualidades do professor.

Mário Braga Henriques formou-se na Faculdade de Direito do Pará, em 11 de agosto de 1927, com apenas 19 anos de idade, realizando o curso de forma impecável, o que lhe valeu o prêmio "Teixeira de Freitas" - uma medalha de ouro -, e o retrato aposto em uma das salas da Faculdade, sendo o primeiro aluno a conquistar tal honraria. Ao matricular-se no curso, em agosto de 1923, não tinha idade legal para iniciá-lo, porém, a Comissão de Exame Vestibular permitiu seuingresso por ter "feito um exame verdadeiramente brilhante" (HENRIQUES, 1932).

Em 1932, aos 24 anos, tornou-se catedrático de Direito Comercial(Henriques, 1932), na mesma faculdade em que se formara, merecendo destaque em revista de circulação nacional (Fon-Fon, 1933, p. 28). Em sua carreira no magistério foi, por vários períodos, diretor da Faculdade de Direito. Licenciado da cátedra exerceu o cargo de consultor jurídico no Banco de Crédito da Amazônia, na agência do Rio de Janeiro, então capital federal (A Província do Pará, 1959, p. 08).

Mesmo com suas qualificações, não era fácil administrar a nova universidade que existia apenasin nomine, constituída por faculdades que sequer eram próximas geograficamente, tendo existido por décadas sem nenhuma ligação. Não havia uma instituição orgânica viva,com um espírito universitário moderno. A união artificial de antigas escolas gerara uma universidade que era apenas uma questão de rótulo.

Embora em uma conjuntura desfavorável, o primeiro ano da universidade pareceu ter corrido bem, sendo o reitor agraciado com uma placa de ouro,para recordar a data. Nasolenidade, dirigida pelo vice-reitor Adarezer Coêlho, vários presentes discursaram, inclusive Silveira Netto, todos expressando a satisfação em comemorar o primeiro ano do gestor, e reconhecendo “....as dificuldades a superar e obstáculos a reduzir que são inerentes e fatalmente se encontram no início de empreendimentos de tamanha envergadura como o instalar de uma Universidade" (Homenageado...A Província do Pará, 30 nov 1958, p.3).

Logo essa fase de lua de mel chegou ao fim,com a Universidade do Pará tornando-se palco de "renhidas disputas verbais nas reuniões do Conselho Universitário, onde os oposicionistas ganhavam terreno, criticando a letargia que dominava as ações 
da instituição" (MEIRA, 2007, p. 492). A oposição vinha da medicina em busca do poder, elogo obtendo sua primeira vitória com a entrada de Affonso Rodrigues Filho, catedrático de Clínica Médica, como vice-reitor, por renúncia do anterior (BECKMANN, 1985, p. 517). Algum tempo depois, o reitor também perdeu o apoio da Faculdade de Direito (A Província do Pará, 1959, p. 10), cujos membros deixaram de comparecer às reuniões do Conselho Universitário até o final de seu mandato (BECKMANN, 1985).

Em 1960, discursando para a Assembleia Universitária no último ano de mandato, Mário Braga Henriques apresentou suas razões para as dificuldades de administrar a nova universidade, que iam desde o projeto de lei da mesma, aprovado sem emendas,resultando em "vários defeitos, agravados posteriormente até por erros de impressão", e até questões como a impossibilidade, na ocasião, de criar uma Cidade Universitária que, pela lei, teria que ser em terreno doado pelo governo do estado ou pela prefeitura, e não havia em Belém nenhum terreno disponível deste porte, salvo em Ananindeua, onde encontrou resistência "verdadeiramente generalizada". A solução seria desapropriar áreas em Belém, não previsto no dispositivo legal, que só permitia a doação (A Província do Pará, 1960, p. 10).

Outro fator era o atrelamento financeiro da universidade à Superintendência de Valorização Econômica da Amazônia (SPVEA), o que rendia uma quantia pequena para uma instituição que precisava crescer, além de frequentes atrasos no repasse das verbas com "constantes de drásticas reduções". Para Braga Henriques "Vivemos, portanto, em regime de penúria, quase mendicância"; e "A sobrevivência, pois, de nossa Universidade (...) nos dois anos decorridos 1958-59, pode-se dizer, foi quase um milagre" (A Província do Pará, 1960, p.10).

O dramático discurso do reitor, é como um pedido de desculpas à posteridade, pedindo para ser julgado pelo pouco que recebeu e o muito que procurou fazer; e que nunca desejou aquele cargo, ao qual fora levado pela "insistência bondosa de meu inesquecível e grande amigo General Joaquim Magalhães Cardoso Barata" (A Província do Pará, 1960, p. 10).

As dificuldades eram reais, além de ser alguém deslocado naquele contexto, um estranho na terra em que nascera, e que não buscou melhorar essa imagem, passando 
boa parte do tempo no Rio de Janeiro, em tese defendendo os interesses da universidade. Esses constantes e longos deslocamentos reforçaram a imagem de um reitor in absentia, conduzindo a instituição com intenso uso de "controle remoto", como recorda Armando Mendes:

\begin{abstract}
As comunicações da época eram precárias, quando se fazia mister entendimento de viva voz com o Magnífico Reitor, era necessário programar conversa pela Radional, na Presidente Vargas, Edifício Bern. Tendo sorte a ligação era completada na hora agendada dias antes, e gritada o suficiente para derrotar ruídos e interferências. Passei por essa rude provação (Mendes, 2007, 41;51).
\end{abstract}

Os estudantes também não pouparam o reitor. No trote dos calouros, onde os cartazes satirizavam diversos fatos, notadamente políticos, em 1960 um cartaz dizia: "Universidade do Pará, expediente do Reitor: 1 dia em Belém e 1 mês no Rio"; outro mencionava o comportamento boêmio de Braga Henriques registrando: "A Universidade do Reitor; Faculdade do Joquei; Faculdade do Pará Clube; Faculdade da Assembléia; Faculdade do Automóvel Clube e todas as festas onde haja uísque" (A Província do Pará, 1959, p. 10).

Bastante desgastado, e talvez por isso não se importando mais com críticas, Braga Henriques tomou uma derradeira atitude considerada polêmica, o que certamente serviu para apagar ainda mais sua memória como gestor.

Em 27 de março de 1960, o Marechal Henrique Teixeira Lott, candidato à presidência, veio a Belém cumprir uma apertada agenda política, que não durou mais que 22 horas (A Província do Pará, 1960, p. 03). Naquela tarde, em auditório completamente lotado, acompanhado do vice-presidente da república João Goulart, do governador do Pará General Moura Carvalho, e outros políticos como Aurélio do Carmo, candidato ao governo do Estado, o Marechal Lott recebeu do magnífico reitor o título de Doutor Honoris Causa,o primeiro outorgado pela Universidade do Pará.

Após pronunciamento sobre o significado do ato, o reitor entregou ao Marechal o diploma que lhe conferiu o título, além de lhe colocar borla e capelo, símbolos da nova 
investidura (Figura 1), a seguir depositando dois beijos em cada lado da face do homenageado ${ }^{7}$. (A Província do Pará, 1960. p. 10).

Figura 01. O primeiro reitor Mário Braga Henriques, à esquerda, cumprimenta o Marechal Henrique Teixeira Lott, primeiro Doutor Honoris Causa da Universidade do Pará.

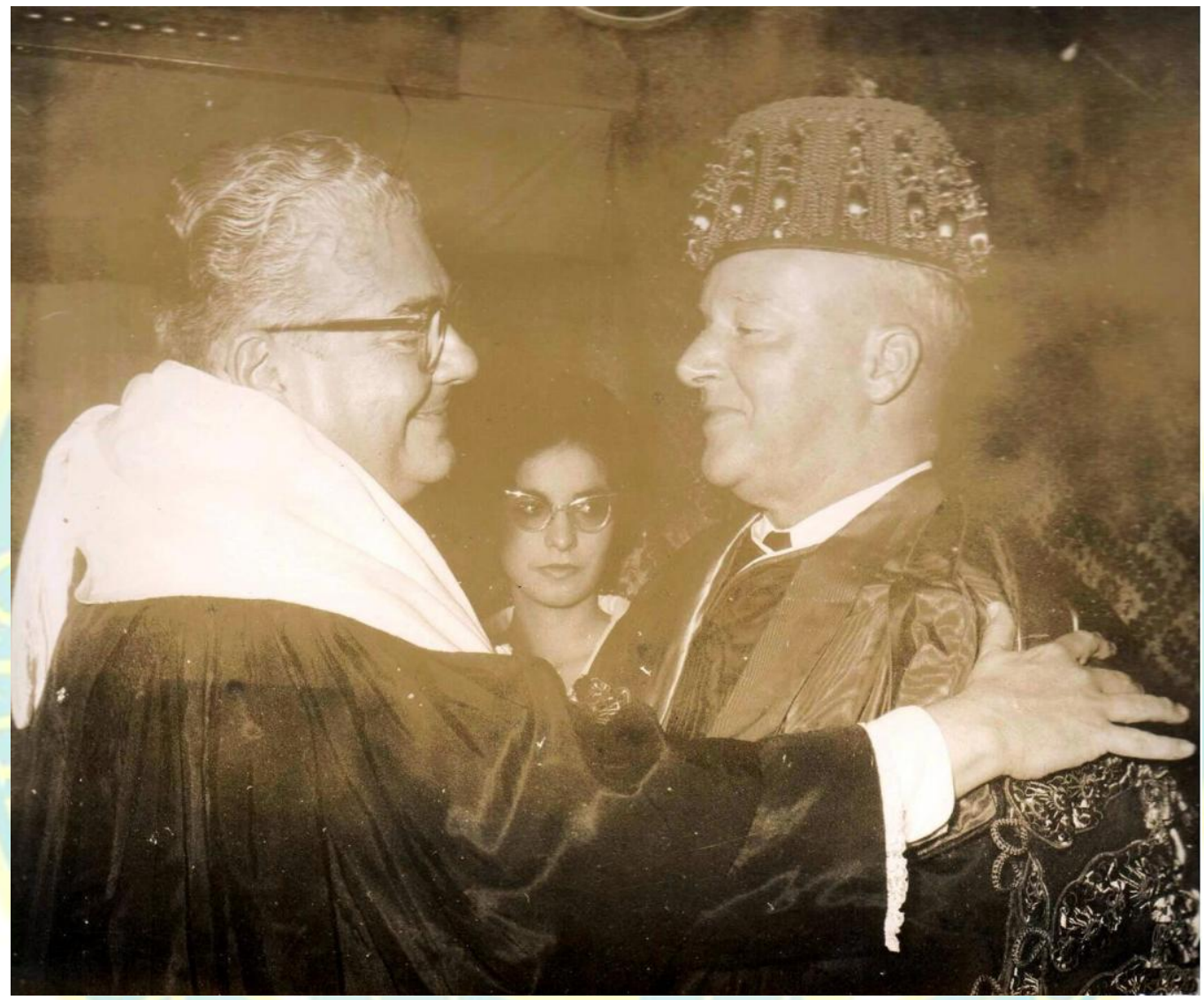

Fonte: Acervo fotográfico da Biblioteca Central da UFPA.

O caráter político do evento foi denunciado dias antes pelo deputado Clóvis Ferro Costa, em artigo em A Província do Paráno qual apontava os problemas financeiros da universidade, que a faziam andar "Capengando, quase como um esmoler (...) arrastando-se no meio a incompreensão dos poderes centrais, que a tratam como a Gata Borralheira dos cursos universitários brasileiros". Aos parcos recursos, somavam-se “desinteligências graves, indispondo mestres e Faculdades", e escolas em disputas de

\footnotetext{
${ }^{7}$ O beijo seguia o protocolo francês para essas ocasiões, segundo Baleixe (2017), gerando comentários jocosos na imprensa do Sudeste. A revista Careta (16 abr 1960) definiu como sabujice; o jornal Tribuna da Imprensa (1 abr 1960) afirmou que na hora do beijo Lott teria exclamado: Homem, não!
} 
hegemonias dificultando a consolidação da instituição. Além disso, a reitoria tinha se entrosado "nos arraiais do situacionismo para dar ao Marechal Henrique Lott (...) um barato título de doutor honoris causa para ser entregue à época de seu primeiro comício em Belém" (Costa, 1960, p. 03).

Ferro Costa mostrou,por meio de documentos, que o diretor da Faculdade de Direito,além de não ter recebido previamente, conforme o regimento, a convocação para a reunião do Conselho Universitário em que seria votado o título a ser outorgado ao marechal, recebera antecipadamente o convite para a titulação de Lott provando ser um jogo de pedras marcadas, uma "fraude tão tranquilamente arquitetada" (Costa, 1960, p. $03)$.

Talvez por conta desse fator político, o primeiro Doutor Honoris Causa da Universidade do Pará ficou esquecido, não sequer registrado no site da instituição (Universidade Federal do Pará, 2018). Diante de uma administração tão pálida e problemática, o destaque do primeiro triênio da Universidade do Pará acabou sendo a cerimônia de instalação da mesma, que tendo ocorrido somente em 1959, ganhou ares de uma nova fundação.

\section{A FESTA QUE DEMOROU A COMEÇAR - A CERIMÔNIA DE INSTALAÇÃO}

Para Moreira (1989), os atos constitutivos mais importantes da universidade realizaram-se no mesmo ano da lei que a criou; do seu estatuto até a nomeação do reitor, tudo ocorreu em 1957. Apenas a instalação solene não seguiu o mesmo ritmo, ocorrendo mais de um ano e meio depois, em 31 de janeiro de 1959, embora a instituição estivesse em atividade desde o ano de sua criação.

Desde antes da nomeação do reitor, ainda em novembro de 1957, o presidente Kubitschek prometera a dirigentes da UAP que naquele mesmo ano a Universidade do Pará seria solenemente instalada e com ele presente (A Província do Pará, 1957, p. 10).

Começava um novo drama, notícias frequentes anunciavam para logo a vinda do presidente à Belém para a cerimônia. Em dezembro de 1957, após as primeiras formaturas pela universidade, o reitor fez a primeira de suas frequentes viagens ao Rio de Janeiro, à serviço da instituição, devendo voltar com o presidente JK para a 
cerimônia de instalação da nova universidade, o que não ocorreu (A Província do Pará, 1957, p. 06).

Em março de 1958 a imprensa noticiou que a instalação solene da universidade não tinha data prevista, continuando as negociações entre a reitoria e a casa civil da Presidência por uma data que o presidente viesse a Belém, considerando que JK chamava a Universidade do Pará de "minha universidade", fazendo"questão de estar entre nós nesse grande dia para a mocidade estudantil paraense" (A Província do Pará, 1958, p. 10). Ainda em março era anunciada para 16 de abril a vinda de JK para a cerimônia de instalação da universidade e inauguração do novo aeroporto (A Província do Pará, 1958, p. 10).

Assim foram se passando os meses. Em novembro de 1958, pelo aniversário de um ano da posse de Braga Henriques, foi anunciado que o presidente enviara um telegrama ao reitor pedindo que "aguardasse sua presença em dia a ser previamente comunicado", para realização da cerimônia (A Província do Pará, 1958, p. 03). No último dia de janeiro de 1959, os jornais publicaram um convite convidando o "corpo discente das entidades que integram a Universidade e quantos se interessem por assuntos culturais" para a inauguração simbólica da Universidade do Pará, no dia do aniversário do terceiro ano do governo JK, com a presença do próprio (A Província do Pará, 1959, p. 10).

Para Fontes (20071), o presidente escolhera vincular a cerimônia ao aniversário de seu governo como resposta ao debate que mobilizava a sociedade então, de que seu governo não dava atenção à educação. Para Moreira (1989), essa vinculação de datas seria a justificativa para o retardamento da solenidade.

Além do presidente, a cerimônia contou com a presença de ministros de Estado e embaixadores junto ao governo brasileiro, altas autoridades federais, o governador do Estado e o prefeito municipal. A mesa foi composta pelo presidente Juscelino Kubitscheck; governador Magalhães Barata;o reitor da Universidade do Brasil (atual UFRJ) Pedro Calmon; o ministro da Guerra, Teixeira Lott; o ministro das Relações Exteriores, Negrão de Lima; o Ministro da Educação e Cultura, Clóvis Salgado; general Nelson de Mello, chefe da casa militar do Presidente da República; professor Antônio Martins Silva, Reitor da Universidade do Ceará; professor Otávio Meira, da Faculdade 
de Direito da Universidade do Pará; ministro Hugo Gouthler, embaixador do Brasil na Bélgica e os embaixadores no Brasil da Suiça e da Bélgica ( A Província do Pará, 1959, p. 01)

Aberta a sessão pelo presidente da República, o Reitor Braga Henriques fez um histórico das faculdades integrantes da nova universidade, sendo seguido por Antônio Martins Filho, reitor da Universidade do Ceará, então a mais jovem universidade do país, que em nome das demais saudou a Universidade do Pará, instituição "que nasce predestinada a ser uma autêntica Universidade da Amazônia", no momento em que o Brasil descobria "a si mesmo e empreende com decisão a marcha para o interior".

Usando da palavra, o ministro da Educação e Cultura, Clóvis Salgado, defendeu o governo ao afirmar ser a universidade uma demonstração que os investimentos referentes ao ensino não ficaram em segundo plano; que "não era possível levar avante um programa de expansão industrial apenas com capitais e equipamentos", sendo “indispensável preparar o homem para manobrá-los e deles tirar o maior proveito". E considerando a fundação do seu primeiro curso superior - Direito - em 1902, a jovem universidade já nascia com 55 anos,com a função de preparar os filhos da terra para explorar e reconhecer as imensas riquezas e potenciais da Amazônia, incorporando-as à economia da nação.

Após citar várias personalidades paraenses do passado, destaques em diversas áreas do conhecimento,afirmou que a universidade não era um presente do governo federal, mas um prêmio que o Pará recebia pelo "seu esforço, à sua capacidade, às infinitas possibilidades de progresso" ( A Província do Pará, 1959, p. 01).

Encerrando a cerimônia, o presidente da República falou de improviso ressaltando a importância do evento, "outra realização de seu governo no setor de ensino", referindo-se à instituição como "sua universidade". Em seguida falou do papel da educação no desenvolvimento da Rússia e dos EUA e discorreu sobre metas de seu governo como a intensificação da Petrobrás e a produção de borracha sintética chegando a prometer uma usina atômica para a Amazônia.

Os discursosmostravam o pensamento do governo sobre o papel que a Universidade do Pará teria em um projeto nacionalista e desenvolvimentista, como força 
canalizadora de progresso e formadora de líderes para a Amazônia. Uma universidade com ação civilizatória sobre a região (FONTES, 2007).

Além de tardia a instalação, pelo menos uma gafe ficou registrada.Em ofício ao diretor da Faculdade de Medicina, em 2 de abril de 1959, o Diretor da Faculdade de Direito, Aloysio Chaves, refere que na cerimônia estava prevista a fala do professor Otávio Meira, membro daquela faculdade, o qual traduzindo o pensamento da Universidade do Pará, faria um pronunciamento em nome da Assembleia Universitária. Os discursos seguiram a ordem natural, entretanto

Quando todos aguardavam - como era do programa - a palavra da Universidade do Pará (...) que era o professor Otávio Augusto de Bastos Meira, dolorosa surpresa contagiou os que se encontravam no Teatro da Paz. S. Exia. O Senhor Presidente da República levantou-se e depois de falar sobre uma universidade de coisas, sem referência especial à novel universidade, encerrou a sessão magna, não concedendo a palavra a quem deveria pronunciar um dos discursos indispensáveis e genuinamente protocolares da cerimônia. (...) No momento em que o hino brasileiro encerrava a solenidade (...) uma profunda emoção de tristeza e angústia se apoderou de todos (...). A mutilação do ato, privando-o de um de seus termos essenciais, tornou-o praticamente, irrealizado (FMUP. Livro de Ofícios recebidos, 1959).

Para a Faculdade de Direito, que registrou em ata essa nota de desagravo, a instalação da Universidade "não passou, na verdade, de puro simbolismo", posto que aos professores da instituição não foi dado direito de falar (FMUP. Livro de Ofícios recebidos, 1959).Otavio Meira fora um dos candidatos à reitoria, que o Governador Magalhães Barata não aceitava. Fica a dúvida se houve apenas falha do cerimonial sem envolvimento de outros fatores. A questão deve ter esfriado ainda mais as relações de Mário Braga Henriques com a Faculdade de Direito.

Em meados de 1960, por compromissos assumidos no Rio, Braga Henriques deixou de vir a Belém, passando o efetivo comando ao Vice-Reitor Affonso Rodrigues Filho. Estava pavimentado o caminho da ascensão de José Rodrigues da Silveira Netto como reitor (Meira, 1985).

$\mathrm{Na}$ lista tríplice, organizada pelo Conselho Universitário para a escolha do reitor, todos os nomes eram da medicina: José Rodrigues da Silveira Netto, Abelardo Santos e Paulo Cordeiro de Azevedo. Agora era a vez da medicina. Mais do que isso, era a vez do Dr. 
Silveira, que foi escolhido pelo presidente JK tomando posse em 19 de dezembro de 1960 e permanecendo no cargo por oito anos e meio (MEIRA, 1985).

Durante a administração de Silveira Netto os estatutos da universidadeforam revistossanando as falhas. Criou-se também o Núcleo Pedagógico Integrado (NPI), uma escola gratuita para filhos de funcionários e professores. Mas, entre as diversas obras, sem dúvida a de maior expressão foi a construção do Campus Universitário, no bairro do Guamá, e que hoje leva seu nome (MEIRA, 2007). A universidade então materializou-se, crescendo em bases físicas, com surgimento de novos cursos e aumento do alunado (Beckmann, 1985, p.518).

Assim transcorreram os primeiros tempos da Universidade Federal do Pará e da sua primeira reitoria, pontos normalmente negligenciados na historiografia oficial da instituição, e que desde os projetos iniciais de criação contou com a participação destacada da Faculdade de Medicina.

\section{REFERÊNCIAS}

A PROVÍNCIA DO PARÁ. Universidade Livre. Belém, 1 de julho, 1924, p. 02.

A PROVÍNCIA DO PARÁ. Universidade Livre. Belém: 10 de julho, 1924, p. 02.

A PROVÍNCIA DO PARÁ UNIVERSIDADE Livre. Belém: 10 de agosto, 1924, p. 02.

A PROVÍNCIA DO PARÁ. Universidade Livre. Belém: 19 de setembro, 1924, p. 02.

A PROVÍNCIA DO PARÁ. Criação da Universidade do Pará com três Faculdades inicialmente. Belém: 06 de agosto, 1952, p. 08.

A PROVÍNCIA DO PARÁ. A Universidade da Amazônia. Belém: 18 de setembro, 1952, p. 08.

A PROVÍNCIA DO PARÁ . Contrário criação das Universidades. Belém: 18 de agosto, 1952. p. 01.

A PROVÍNCIA DO PARÁ. Criação da Universidade do Pará. Belém: 21 de novembro, 1954. p.16.

A PROVÍNCIA DO PARÁ. Empenho para aprovação sem emendas da criação da Universidade do Pará. Belém: 19 de fevereiro, 1956, p.16.

A PROVÍNCIA DO PARÁ. Urgência para a Universidade do Pará. Belém: 10 de maio, 1956, p.1 
A PROVÍNCIA DO PARÁ. Vai à sanção o projeto da Universidade do Pará. Belém: 22 de junho, 1957. p.1

A PROVÍNCIA DO PARÁ. Viajou para o Rio o reitor da Universidade. Belém: 12 de dezembro, 1957, p. 06.

A PROVÍNCIA DO PARÁ. Vice-diretor da Universidade do Pará. Belém: 15 de dezembro, 1957. p.12.

A PROVÍNCIA DO PARÁ. Esperada para quarta-feira a nomeação do reitor da Universidade. Belém: 27 de outubro, 1957, p. 08.

A PROVÍNCIA DO PARÁ. Até 15 de abril estará criada a Universidade da Amazônia. Belém: 21 de março, 1957. p. 09.

A PROVÍNCIA DO PARÁ. Organização da Universidade. Belém: 10 de maio, 1957, p.10.

A PROVÍNCIA DO PARÁ. Poderá entrar em funcionamento este ano a Universidade do Pará. Belém: 13 de agosto, 1957, p. 08.

A PROVÍNCIA DO PARÁ. Primeiros graduados pela Universidade do Pará. Belém: 10 de dezembro, 1957. p.12.

A PROVÍNCIA DO PARÁ. Pronta a lista tríplice. Belém: 20 de outubro, 1957, p. 08.

A PROVÍNCIA DO PARÁ. No plenário esta semana, o projeto da Universidade. Belém: 16 de maio, 1957. p.3

A PROVÍNCIA DO PARÁ. Sancionada a Universidade do Pará. Belém: 03 de julho, 1957. p. 01 .

A PROVÍNCIA DO PARÁ. Instalação da Universidade ainda em 1957. Belém: 08 de novembro, 1957, p.10.

A PROVÍNCIA DO PARÁ. Juscelino visitará Belém na segunda quinzena de abril. Belém: 13 de março, 1958, p.10

A PROVÍNCIA DO PARÁ. Sem data a instalação solene da Universidade. Belém: 06 de março, 1958, p. 10 .

A PROVÍNCIA DO PARÁ Homenageado ontem o Reitor da Universidade. Belém: 30 de novembro, 1958, p. 03.

A PROVÍNCIA DO PARÁ. Realizado ontem o "trote" com perto de 200 "calouros" nas ruas. Belém: 19 de abril, 1959. p.10.

A PROVÍNCIA DO PARÁ. Universidade do Pará: instrumento definitivo de conquista da planície. Belém: 01 de fevereiro, 1959, p. 01. 
A PROVÍNCIA DO PARÁ. A congregação da Faculdade de Direito, em sessão especialmente convocada por seu diretor, desagrava o magnífico reitor da Universidade do Pará. Belém: abril, 1959, p. 10.

A PROVÍNCIA DO PARÁ. Dr. MÁRIO Braga Henriques. Belém: 10 de fevereiro, 1959, p. 08.

A PROVÍNCIA DO PARÁ. A sobrevivência da Universidade no período inicial foi quase um milagre. Belém: 06 de março, 1960, p.10

A PROVÍNCIA DO PARÁ. Passou 22 horas em Belém, o Marechal Lott. Belém: 29 de março, 1960, p. 03.

A PROVÍNCIA DO PARÁ. Precisa esta Universidade expandir-se para maior glória da cultura paraense. Belém: 29 de março, 1960. p.10.

BALEIXE, Haroldo. O Marechal Lott foi Doutor Honoris Causa pela UFPA em 1960. Blog da Faculdade de Arquitetura e Urbanismo (FAU/UFPA). Disponível em: https://fauufpa.org/2017/12/24/o-marechal-teixeira-lott-foi-doutor-honoris-causa-pela-ufpa-em1960/. Acesso em 17 dez. 2018.

BRASIL. Decreto $\mathrm{n}^{\circ}$ 19.851, de 11 de abril de 1931. Dispõe sobre o ensino superior no Brasil. Disponível em <http://www2.camara.leg.br/legin/fed/decret/1930-1939/decreto-19851-11-abril1931-505837-publicacaooriginal-1-pe.html>. Acesso em 11 out 2018.

BRASIL. Projeto de lei 2268/1952. Disponível em <http://www.camara.gov.br/proposicoesWeb/fichadetramitacao?idProposicao=201644 >. Acesso em 15 out. 2018.

BRASIL. Lei n ${ }^{\circ}$ 9.394, de 20 de dezembro de 1996. Estabelece as diretrizes e bases da educação nacional (LDBN). Disponível em <https://www2.senado.leg.br/bdsf/bitstream/handle/id/70320/65.pdf>. Acesso em 11 out 2018

BECKMANN, Clodoaldo. Apontamentos para a História da Universidade Federal do Pará. In: BECKMANN, Clodoaldo; BASSALO, José Maria Filardo; et alli (Orgs.). Anais do Simpósio sobre a História da Ciência e da Tecnologia no Pará. Tomo II. Belém: GEU-UFPA, 1985.

BECKMANN, Clodoaldo. José da Silveira Neto. O homem-época da UFPA. 1916-1998. ParáMédico. Vol.8. N.1. Set/Out. 2001.

CAMPOS, Epílogo de. Entrevista para o documentário UFPA 30 anos. Belém: Associação dos Docentes da UFPA (ADUFPA), 1987.

CARNEIRO, Oziel. Entrevista com Tito Barata para o canal Conexão Belém do Pará, 2012. Disponível em :https://www.youtube.com/watch?v=gGd3Q6pFt3Q. Acesso em: 25 nov 2018.

CONFERÊNCIA do Dr. Oscar de Carvalho. Rev A Semana, ano VII, n.341, 1 nov 1924, s.p.

A PROVÍNCIA DO PARÁ . Contrário criação das Universidades. Belém: 18 de agosto, 1952. p. 01. 
COSTA, Clóvis Ferro. A Universidade do Pará e a política. A Província do Pará, Belém, 20 de março, 1960, p. 03.

DIÁRIO DE SÃO LUIZ. Serviço Telegraphico. São Luiz: 10 de maio, 1924, p.4.

ESTADO DO PARÁ. Indicados os candidatos a reitoria da Universidade. Belém: 20 de outubro, 1957, p.6.

ESTADO DO PARÁ. O governador Magalhães Barata transmite impressões de sua visita à Faculdade de Medicina. Belém: 23 de agosto, 1957, p.2.

ESTADO DO PARÁ. Universidade Livre. Belém, 17 de maio, 1924, p.2.

FACULDADE DE MEDICINA DA UNIVERSIDADE DO PARÁ. Livro de Ofícios Recebidos, Belém [s.n], 1959.

FACULDADE DE MEDICINA E CIRURGIA DO PARÁ. Livro de Ofícios Expedidos, Belém [s.n], 1931.

FACUlDADE DE MEDICINA E CIRURGIA DO PARÁ. Parecer do Dr. Carlos Arnóbio Franco, Belém [s.n], 1942

FON-FON, Rio de Janeiro, 27 de maio de 1933, p. 28.

FONTES, Edilza Joana. A Invenção da Universidade Federal do Pará. In: FONTES, Edilza Joana (Org.). UFPA 50 anos. Histórias e Memórias. Belém: EDUFPA, 2007.

HENRIQUES, Mário Braga. Das Sociedades Mercantis Irregulares. Tese para concurso a professor catedrático da $2^{\mathrm{a}}$ cadeira de Direito Comercial apresentada à Faculdade de Direito do Pará. Belém: Livraria Pará, 1932.

LEÃO, Acilino de. Faculdade de Medicina e Cirurgia do Pará. Relatório do ano de 1944 apresentado à Congregação pelo Diretor Dr. Acilino de Leão em sessão de 2 de janeiro de 1945. Belém: Ofícinas Gráficas da Revista de Veterinária, 1945.

MELLO, Alex Bolonha Fiúza de. (Org). UFPA 50 Anos. Os Estatutos da UFPA. Edição Histórica. Belém: EdUFPA, 2007.

MENDES, Armando Dias. A Pré-História da UFPA à luz do argumento da sua visceral amazoniedade. In: MELLO, Alex Bolonha Fiúza de (org.). UFPA 50 anos. Relatos de uma trajetória. Belém: EDUFPA, 2007.

MEIRA, Alcyr. Um indômito timoneiro. In: José da Silveira Netto: o reitor que pensou no futuro. Catálogo do acervo da Biblioteca particular do Prof. Dr. José Rodrigues da Silveira Netto, ex-reitor da Universidade Federal do Pará, dez. 1960 - jul. 1969 / Universidade Federal do Pará. - Belém: EDUFPA, 2007.

MEIRA, Clóvis. Barata no Centenário. Belém: Imprensa Oficial, 1989.

MEIRA, Clóvis. E o Epílogo partiu. O Liberal, Belém, 12 nov 1992. p.8 
MIRANDA, Aristóteles Guilliod de; ABREU JR, José Maria de Castro. Memória Histórica da Faculdade de Medicina e Cirurgia do Pará 1919-1950. Da fundação a federalização. Edição dos autores, 2009.

MIRANDA, Aristoteles Guilliod de. A epidemiologia das doenças infecciosas no início do século XX e a criação da Faculdade de Medicina e Cirurgia do Pará. Tese (Doutorado) Universidade Federal do Pará, Instituto de Ciências Biológicas, Programa de Pós-Graduação em Biologia de Agentes Infecciosos e Parasitários- Belém: [s. n.], 2013.

MOREIRA, Eidorfe. Para a História da Universidade Federal do Pará (Panorâma do primeiro decênio), 1977. In: Obras reunidas de Eidorfe Moreira. Vol. V. Belém: CEJUP, 1989.

OLIVEIRA, Alfredo. A Pedra Verde. Belém: Falangola, 1986.

PINTO, Walter. Das faculdades isoladas à criação da UFPA. Beira do Rio. Ano IV, N.51- junjul, 2007. p. 03.

ROCQUE, Carlos. Magalhães Barata. O homem, a lenda, o político. Vol.2. Belém: SECULT, 2006.

SÁ, Dominichi Miranda de. A Ciência como Profissão. Médicos, bacharéis e cientistas no Brasil (1895-1935). Rio de Janeiro: Ed. Fio-Cruz, 2006.

SEMANA IV do Acadêmico de Medicina. Revista do Acadêmico de Medicina. Ano XIX, N.9. Nov. 1952.

UMA UNIVERSIDADE Paraense. Pacotilha, Maranhão, 9 mai 1910 p.2.

UNIVERSIDADE. Estado do Pará, Belém, 14 mai 1912, p.1.UNIVERSIDADE do Pará. A Província do Pará, Belém, 31 jul. 1955, p.2

UNIVERSIDADE FEDERAL DO PARÁ. Secretaria Geral dos Conselhos Superiores Deliberativos. Títulos Honoríficos Outorgados. Disponível em http://www.ufpa.br/sege/titulos_honorificos.html. Acessado em $21 \mathrm{dez} 2018$.

Trabalho enviado em: 26/01/2019

Trabalho aceito em: 04/06/2019 